International Journal of Current Advanced Research

ISSN: O: 2319-6475, ISSN: P: 2319 - 6505, Impact Factor: SJIF: 5.995

Available Online at www.journalijcar.org

Volume 6; Issue 3; March 2017; Page No. 2894-2897

DOI: http://dx.doi.org/10.24327/ijcar.2017.2897.0135

Research Article

\title{
KNOWLEDGE, ATTITUDE AND PRACTICE AMONG DENTAL PRACTITIONERS REGARDING ADHESIVES IN PATIENTS WEARING MAXILLOFACIAL PROSTHESIS
}

\author{
Karthikeson P.S., Dhanraj.M and Ashish.R.Jain ${ }^{3}$
}

Department of Prosthodontics, Saveetha Dental College and Hospital, Chennai, India

\section{A R T I C L E I N F O}

Article History:

Received $20^{\text {th }}$ December, 2016

Received in revised form $24^{\text {th }}$ January, 2017

Accepted $4^{\text {th }}$ February, 2017

Published online $28^{\text {th }}$ March, 2017

\section{Key words:}

Knowledge, Adhesives, Maxillofacial

Prosthesis, Survey, Questionnaire

\begin{abstract}
A B S T R A C T
Background: Satisfying the expectations of maxillofacial patients for optimal esthetics and stability is often beyond the technical skills of even the most accomplished practitioners. Knowing the use of denture adhesives may help to satisfy the expectations of specific patients and achieve their intended treatment goals.

Aim: To create awareness in dental practitioners about the adhesives given to patients wearing Maxillofacial Prosthesis.

Materials and methods: A random sample of 100 dental practitioners was selected and included for this study. The survey questions focused on knowledge, attitude and practice of adhesives given to patients wearing Maxillofacial Prosthesis. The dental practitioners had minimum of one year of clinical experience after their dental education.

Results: $60 \%$ of the dental practitioners were aware of adhesives given to patients wearing Maxillofacial Prosthesis and $40 \%$ of the dental practioners were not aware of adhesives. In this survey, dental practitioners were more aware of types of adhesives given to the patient particularly the adhesive epithane -3 and cosmetics and functional rehabilitation. $40 \%$ of the dental practitioners were unaware about the duration and side effects of adhesives in Maxillofacial Prosthesis patients.

Conclusion: Unawareness of the dental practioners regarding adhesives in Maxillofacial prosthetic patient may be due to lack of knowledge and practise. This can be improved by continuing dental education programs and highlight the adhesives in Maxillofacial Prosthesis.
\end{abstract}

Copyright@2017 Karthikeson P.S., Dhanraj.M and Ashish.R.Jain. This is an open access article distributed under the Creative Common Attribution License, which permits unrestricted use, distribution, and reproduction in any medium, provided the original work is properly cited.

\section{INTRODUCTION}

Maxillofacial defects may be a result of congenital malformations, trauma or surgical resection of tumors. ${ }^{[1],[2]}$ The primary objective of rehabilitating these defects is to eliminate the disease and to improve the quality of life for these individuals. ${ }^{[3],[4],[5]}$ Among various maxillofacial defects, intra oral defects in the form of clefts and opening into the palate are very common. Several methods have been advocated for reconstructing these defects. The use of an obturator prosthesis is one of them ${ }^{[6]}$. Effective obturation of maxillary defects produces sufficient separation of the oral and nasal cavity to improve the quality and intelligibility of speech. It also enhances masticatory function, deglutition and esthetics. ${ }^{[7],[8],[9]}$ The weight of maxillary obturator prosthesis is often a factor to be considered with respect to retention and comfort of the patient. Hence it is desirable to design light weight prosthesis ${ }^{[10],[11],[12]}$. Prosthetic intervention should occur at the time of surgical resection and will be necessary for the remainder of the patient life.

*Corresponding author: Karthikeson P.S Department of Prosthodontics, Saveetha Dental College and Hospital, Chennai, India
However Maxillofacial Prosthesis is not uncomfortable for some patients with mouth lesions.In order to give full support, adhesives can be given to reduce irritation while wearing maxillary obituary Prosthesis. The success of most maxillofacial prostheses depends on retention by medical adhesives. Products such as Smith-Nephew's Skin-Prep (SP) are available that can be used on the skin that could improve prosthesis adhesion protective dressing. The removal of adhesive from the skin is also problematic, so solvents, such as Uni-Solve adhesive remover (US), are often used.

\section{MATERIALS AND METHODS}

A questionnaire was distributed to 100 dental practioners to provide knowledge about adhesive in patients wearing maxillofacial prosthesis (Table 1). The questionnaire is prepared based on knowledge about adhesives given to patients wearing maxillofacial prosthesis. The questionnaire involved type of adhesives, duration of adhesives, types of Maxillofacial prothesis, about its cosmetic and functional rehabilitation and whether it causes side effects. The questionnaire contained 10 questions and was distributed through online link using survey planet and it was circulated to the practitioners. The results were statistically analysed. 
Tables 1 Survey Questionnaire

\begin{tabular}{|c|c|c|}
\hline Questions & Choices & Percentage \\
\hline \multirow{3}{*}{$\begin{array}{l}\text { 1.Are you aware of Maxillofacial } \\
\text { Prosthesis? }\end{array}$} & 1)Yes & $70 \%$ \\
\hline & 2) $\mathrm{No}$ & $30 \%$ \\
\hline & 1)Intraoral & $2 \%$ \\
\hline \multirow{3}{*}{$\begin{array}{l}\text { 2. What are the types of maxillofacial } \\
\text { Prosthesis? }\end{array}$} & 2)Extra oral & $5 \%$ \\
\hline & 3)Both & $60 \%$ \\
\hline & 4)Don't know & $33 \%$ \\
\hline \multirow{2}{*}{$\begin{array}{l}\text { 3.Does it improve the cosmetic and } \\
\text { functional rehabilitation? }\end{array}$} & 1)Yes & $63 \%$ \\
\hline & 2) No & $37 \%$ \\
\hline \multirow{2}{*}{$\begin{array}{l}\text { 4.Does Maxillofacial Prosthesis leads to } \\
\text { any side effects? }\end{array}$} & 1)Yes & $50 \%$ \\
\hline & 2)No & $50 \%$ \\
\hline \multirow{2}{*}{$\begin{array}{l}\text { 5.Are you aware of the adhesives used in } \\
\text { Maxillofacial Prosthesis patients? }\end{array}$} & 1)Yes & $58 \%$ \\
\hline & 2) No & $42 \%$ \\
\hline \multirow{2}{*}{$\begin{array}{l}\text { 6.Do you know the duration of adhesives } \\
\text { after applying to patients? }\end{array}$} & 1)Yes & $18 \%$ \\
\hline & 2) No & $82 \%$ \\
\hline \multirow{4}{*}{$\begin{array}{l}\text { 7.Are you aware of the types of adhesives } \\
\text { given to patients? }\end{array}$} & 1)Yes & $66 \%$ \\
\hline & 2) No & $34 \%$ \\
\hline & 1)Skin prep & $12 \%$ \\
\hline & 2)Secure medical & $5 \%$ \\
\hline \multirow{2}{*}{ 8.If yes, Which adhesive do you prefer? } & 3)Epithane-3 & $63 \%$ \\
\hline & 4)Don't know & $20 \%$ \\
\hline
\end{tabular}

Once the questionnaire were completed, a basic lecture about adhesives in Maxillofacial Prosthesis.

\section{RESULTS}

In the present study, the questionnaire was distributed to 100 dental practitioners. Majority of the practitioners (70\%) were aware of maxillofacial prosthesis, while the others were unaware (Figure 1).

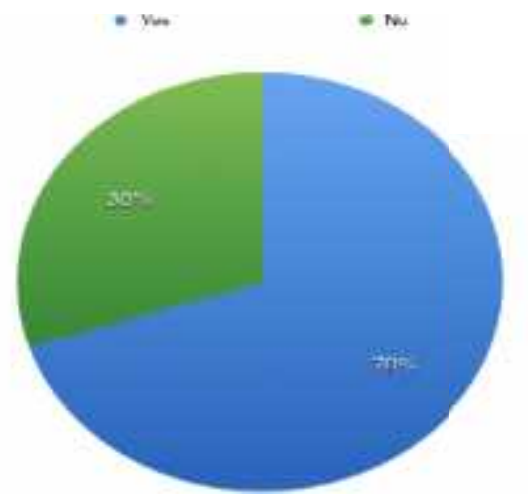

Figure 1 Are you aware of Maxillofacial Prosthesis?

Most of the practitioners $(60 \%)$ answered that both intraoral and extraoral are the types of maxillofacial prosthesis, few people (33\%) do not know the types (Figure 2).

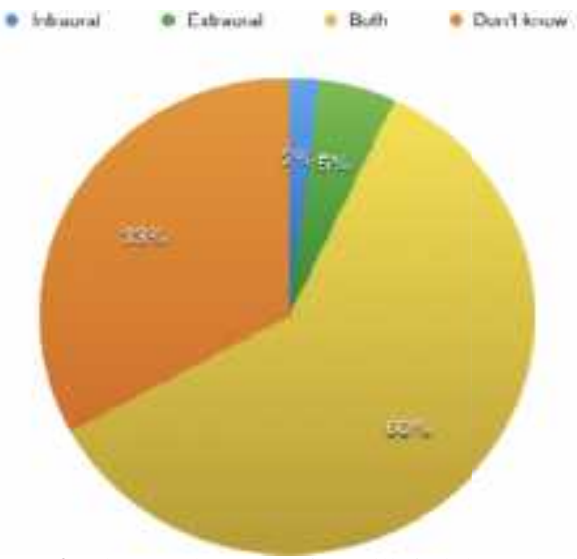

Figure 2 What are the types of Maxillofacial prosthesis?

Maximum of the practitioners $(67 \%)$ explained that it improves cosmetic and functional rehabilitation (Figure 3 ).

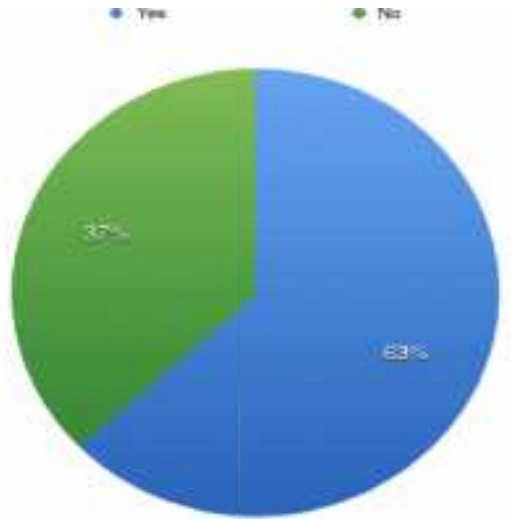

Figure 3 Does it improve the cosmetic and functional rehabilitation?

The practitioners described that there are equal chances $(50 \%)$ for maxillofacial prosthesis both having and not having side effects (Figure 4).

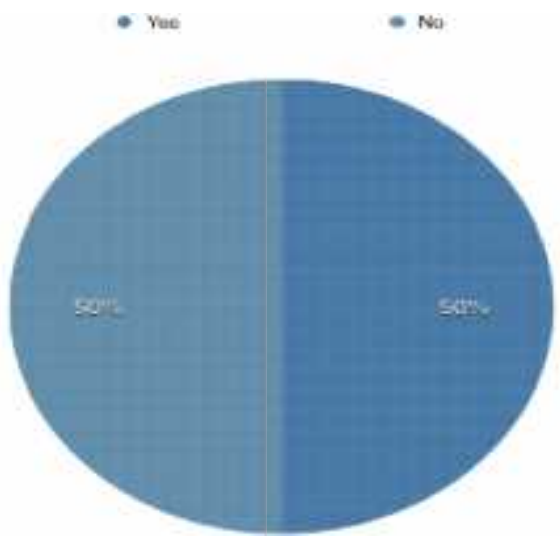

Figure 4 Does Maxillofacial Prosthesis leads to any side effects?

Majority of the practitioners $(58 \%)$ were aware that adhesives are used in the maxillofacial prosthesis (Figure 5).

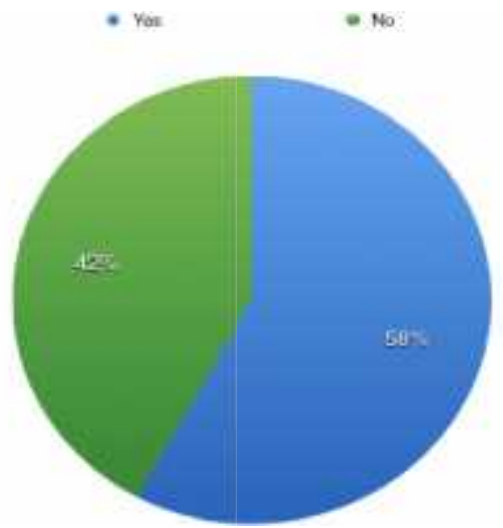

Figure 5 Are you aware of adhesives used in Maxillofacial Prosthesis patients?

$82 \%$ of dental practitioners were not known about the duration of adhesives in maxillofacial prosthesis (Figure 6). $67 \%$ of dental practitioners were aware of the types of adhesives given to patients (Figure 7). 63\% of dental practitioners chose epithane-3 type of adhesive while few of them $(20 \%)$ did not know about the types of adhesives used (Figure 8). 


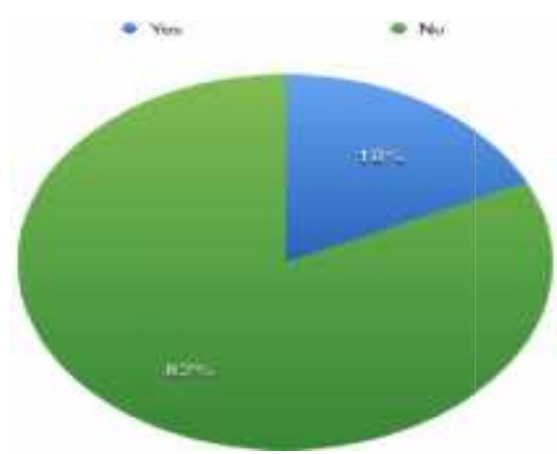

Figure 6 Do you know the duration of adhesives after applying to patients?

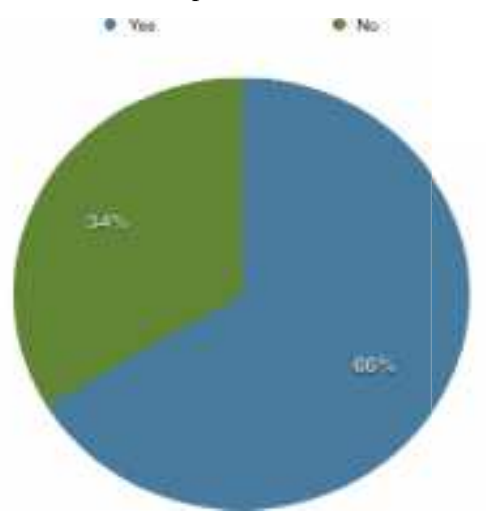

Figure 7 Are you aware of the types of adhesives given to patients?
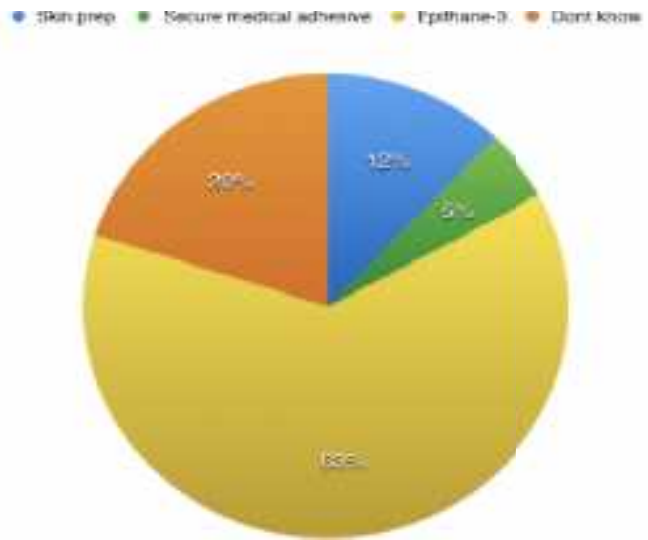

Figure 8 If yes, Which adhesive do you prefer?

\section{DISCUSSION}

There are many studies which explains about Maxillofacial prosthesis and its recent advances. Dr.Amol R.Barhate (Rural dental college, Loni) has done systematic review on Maxillofacial prosthesis. Seema Pattanaik and Aarti P. Wadkar has done research on Rehabilitation of a Patient with an Intra Oral Prosthesis and an Extra Oral Orbital Prosthesis Retained with Magnets. Dr.Rohit Ragavan has done a review on recent advances on Maxillofacial Prosthesis. This study describes about alginates used in Maxillofacial Prosthesis. Another important study done by Marcelo Coelho Goiato is the patient satisfaction with maxillofacial prosthesis. It was a review where patients with Maxillofacial defects were given aesthetical maxillary obituary Prosthesis. ${ }^{[13]}$ Rehabilitation through alloplasty or prosthetic restoration provides satisfactory conditions in aesthetics and well-being and reinstates individuals in familial and social environment. ${ }^{[14],[15]}$. The success rate of Maxillofacial prosthesis for the patients was nearly 60-70\% But some patients with skin irritation felt uncomfortable in wearing Maxillofacial Prosthesis. In the present study, applying adhesives like epithane -3 and secure medical adhesives, it will significantly reduce skin irritations and provide $100 \%$ success rate for patients wearing maxillofacial prosthesis. Many of the dental practioners were aware of adhesives given to maxillofacial prosthesis wearing patients but they are unaware of duration of adhesives after applying to patients. So this study will help for future dental practioners in finding out the advancements about adhesives and achieving higher success rate with patients wearing maxillofacial Prosthesis at ease.

\section{CONCLUSION}

Most of the dental practitioners were aware about the maxillofacial Prosthesis but still knowledge on clinical skills is necessary to prevent the prosthesis failure in terms of retention and stability. Further awareness would enhance the efficacy of usage and overcome the difficulties faced while practicing among dental practitioners.

\section{Reference}

1. Beumer J, Curtis T, Marunick M. Maxillofacial rehabilitation: prosthodontic and surgical considerations. St Louis: Ishiyaku EuroAmerica, Inc.; 1996:240-285.

2. Lapointe HJ, Lampe HB, Taylor M. Comparison of maxillectomy patients with immediate versus delayed obturator prosthesis placement. J Otolaryngol. 1996; 25: 308-312.

3. Lang BR, Bruce RA. Presurgicalmaxillectomy prosthesis. J Prosthet Dent. 1967; 17: 613-619.

4. Aramany MA. Basic principles of obturator design for partially edentulous patients. Part I: Classification. $J$ prosthet dent. 2001; 86(6): 559-561.

5. Aramany MA. Basic principles of obturator design for partially edentulous patients. Part II: Design principles. J prosthet dent. 2001; 86(6): 562-568.

6. Gregory RP, Greggory ET, and Arthur OR, Prosthodontic principles in the framework design of maxillary obturator prostheses. J Prosthet Dent 2005; 93: 405-411.

7. Shaker KT. A simplified technique for construction of an interim obturator for a bilateral total maxillectomy defect. Int J Prosthodont. 2000; 13: 166-168.

8. YoavGrossmann, and IgalSavion. The use of a light polymerized resin-based obturator for the treatment of the maxillofacial patient. J Prosthet Dent 2005; 94: 289-292.

9. Mark A. Pigno, Conventional prosthetic rehabilitation after free flap reconstruction of a maxillectomy defect: A clinical report. J Prosthet Dent 2001; 86: 578-581.

10. Won-suck Oh and Eleni D. Roumanas. Optimization of Maxillary Obturator Thickness Using a DoubleProcessing Technique. Journal of Prosthodontics. 2008, 17: 60-63.

11. Cordeiro Pg, Santamaria E. A classification system and algorithm for reconstruction of maxillectomy and midfacial defects. PlastreconstrSurg 2000; 105: 233146. 
12. Haug, S. P., Richard, G. E., Margiotti, E., Winkler, M. M., \& Moore, D. J. (1995). An In Vivo Evaluation of Adhesives Used in Extraoral Maxillofacial Prostheses. Journal of Prosthodontics,4(1), 11-15.

13. Kiat-Amnuay, S., Gettleman, L., \& Goldsmith, L. J. (2004). Effect of multi-adhesive layering on retention of extraoral maxillofacial silicone prostheses in vivo. The Journal of Prosthetic Dentistry,92(3), 294-298.
14. Montgomery, P. C., \&Kiat-Amnuay, S. (2009). Survey of Currently Used Materials for Fabrication of Extraoral Maxillofacial Prostheses in North America, Europe, Asia, and Australia. Journal of Prosthodontics, 19(6), 482-490.

15. Bodine, R. L. (1929). Maxillofacial prosthesis Extraoral prostheses. International Journal of Orthodontia, Oral Surgery and Radiography, 15(4), 371-380.

\section{How to cite this article:}

Karthikeson P.S et al (2017) ' Knowledge, Attitude And Practice Among Dental Practitioners Regarding Adhesives In Patients Wearing Maxillofacial Prosthesis', International Journal of Current Advanced Research, 06(03), pp. 2894-2897.DOI: http://dx.doi.org/10.24327/ijcar.2017.2897.0135 